\title{
A vinculação constitucional de recursos para a saúde: avanços, entraves e perspectivas
}

\author{
Constitutional binding of resources for the health \\ sector: breakthoughs, barriers and perspectives
}

\footnotetext{
1 M inistério da Saúde, Sistema de Informações sobre Orçamentos Públicos em Saúde.

Rua Joaquim Nabuco 186/ 301, I panema, 20080-030 Rio de Janeiro RJ. afaveret@iis.com.br
}

Abstract As in other public policies, financing is a powerful element which induces strategies and actions in the health sector. On one hand, the financial decentralization put forward by the Federal Constitution of 1988 allowed municipalities to effectively take charge of their financing role in the health policy. On the other hand, during the first half of nineties, there was great instability of the federal financing of health. The Constitutional Amendment n. 29/00, which binds fiscal resources to expenditures with public health services and actions, was the way out of this situation. Its effective implementation, however, depend upon the advances in the understanding of the terms of the Constitution by the actors in the public health sector. N onetheless, it is already possible to estimate that the share of the states in the financing of public health will improve greatly, while the federal government share will decrease and the municipalities will, in average, maintain their current level of public spending in health. This may imply that subnational governments will have greater autonomy in the design and implementation of health policies.

Key words $\mathrm{H}$ ealth policy, Public health, Financing, U nified H ealth System
Resumo Como em outras políticas públicas, 0 financiamento é um poderoso elemento indutor de estratégias e ações de saúde. Se, por um lado, a descentralização financeira promovida pela Constituição Federal de 1988 possibilitou aos municípiosa assumirem efetivamente parte do financiamento da política de saúde, por outro lado, na primeira metade da década passada, houve grande instabilidade do financiamento federal da saúde. A Emenda Constitucional n. 29/00, ao vincular recursos tributários de estados e municípios a despesas com ações e serviços públicos de saúde, foi a solução encontrada para o quadro. A sua real implementação, contudo, depen de dos avanços nos entendimentos do texto constitucional pelo conjunto de atores da política de saúde. Desde logo, contudo, estima-se que a participação dos estados no financiamento da saúde aumente substancialmente, reduzindo-se a fatia da U nião, e havendo manutenção dos níveis médios atuais de gastos municipais. Essa situação poderá implicar maior grau de autonomia das esferas subnacionais na definição e implementação da política de saúde.

Palavras-chave Política de saúde, Saúde pública, Financiamento, Sistema Ú nico de Saúde 


\section{Introdução}

A discussão da implementação do Sistema Ú nico de Saúde (SUS) no Brasil está intimamente ligada aos aspectos relativos às formas de financiamento setorial desenhadas pelo M inistério da Saúde. É por meio delas que, desde o início da década de 1990, estados e municípios têm acesso aos recursos federais de modo mais ou menos automático, de acordo com as condições de gestão estabelecidas pelas $N$ ormas $O$ peracionais do SUS e, mais recentemente, pela N orma O peracional da Assistência à Saúde (NOAS).

Em que pesem os grandes avanços nos processos decisórios no âmbito do SUS, incluindo a implantação de instâncias deliberativas intergovernamentais - as Comissões Intergestores Tripartite e Bipartite, e o funcionamento dos Conselhos de Saúde nas três esferas de governo, acredita-se que a organização da política e, inclusive, o modelo assistencial preconizado pela União vêm sendo implementados por estados e municípios majoritariamente através da normatização federal a respeito de repasses de recursos que são, ainda que em diferentes graus, dirigidos a objetivos específicos.

Disso decorre a importância da análise do quadro atual de regulamentação da Emenda Constitucional n. 29/00 que, aprovada em setembro de 2000, vinculou receitas das três esferas de governo para os gastos em ações e serviços de saúde, consolidando o co-financiamento na política de saúde. Os novos dispositivos constitucionais trazem em si, portanto, a possibilidade de ganhos de autonomia para estados e municípios, através de aumentos no aporte de recursos não necessariamente regidos pelas regras federais.

\section{A EC 29/00: Co-financiamento e estabilidade do SUS}

Em que pesem as diversas questões de natureza tributária que têm implicação positiva ou negativa sobre as fontes de financiamento tradicionais da saúde e, também, a complexa interação entre o Orçamento Geral da União (OGU) e o Orçamento da Seguridade Social (OSS), a criação do SU S em 1988 associou ao conjunto de entes federados, mediante a diretriz de descentralização, a responsabilidade pelo financiamento e gestão do sistema. Contudo, na primeira metade da década de 1990, o governo federal continuava responsável por cerca de $70 \%$ dos recursos financeiros destinados à saúde.
A partir de 1993, particularmente com a especialização da folha de salários no financiamento dos gastos previdenciários do Instituto $N$ acional do Seguro Social (INSS) e, mais recentemente, com a competição do Ministério da Previdência pelas demais contribuições sociais, o estabelecimento de fontes estáveis para o financiamento público da saúde tornou-se ainda mais essencial. Afinal, a estabilidade de gastos é um dos principais requisitos na garantia da manutenção de um sistema baseado no financiamento público e na cobertura universal.

Do reconhecimento dessa necessidade surgiram várias propostas de emendas à Constituição Federal (PECS) visando garantir tais recursos, sendo uma delas finalmente aprovada pelo Senado Federal, em 13 de setembro de 2000. Trata-se da Emenda Constitucional n. 29/00.

A nova norma constitucional define um patamar mínimo inicial, para 2000, de $7 \%$ das receitas municipais e estaduais a serem aplicadas em saúde e um acréscimo de $5 \%$ sobre o montante empenhado pelo M inistério da Saúde em 1999.

N os anos seguintes, até 2004 , os percentuais previstos para estados e municípios deverão elevar-se até atingir $12 \%$ das receitas estaduais e $15 \%$ das receitas municipais, enquanto a participação da União será corrigida pela variação nominal do Produto Interno Bruto (PIB).

Dadas as diferentes regras de crescimento das vinculações estabelecidas para as diversas esferas de governo, uma avaliação precisa do montante de recursos adicionais que a implementação da emenda trará ao sistema público de saúde depende da antecipação da evolução das receitas públicas de estados e municípios, e do crescimento do PIB, no caso dos recursos da União.

Se é verdade que a vinculação tem o inegável mérito de comprometer efetivamente as três esferas de governo com o financiamento da saúde, além de atenuar a usual instabilidade da receita, enesse sentido constitui um avanço euma promessa de defesa do orçamento da saúde, diversos entraves ainda deverão ser superados para a sua real implementação.

Desses entraves fazem parte não apenas questões ligadas à concepção do novo dispositivo constitucional, em especial no que diz respeito ao OSS, mas também em relação à compreensão pelo conjunto de atores da política de saúde, aí incluídos os órgãos de controle nos três níveis de governo, sobre as definições nele contidas. 


\section{Avanços e entraves na regulamentação da EC 29/00}

A regulamentação do novo texto constitucional deverá ser feita através de lei complementar. As negociações para a elaboração da lei, embora sob a responsabilidade do Poder Legislativo, vêm sendo conduzidas, desde2001, pelo próprio Ministério da Saúde, que tem como principal interlocutor e parceiro o Conselho Nacional de Saúde. O utros órgãos vêm também participando do processo, com destaque para os Conselhos de Secretários Estaduais de Saúde (Conass) e de Secretários M unicipais de Saúde (Conasems), a Comissão de Seguridade Social da Câmara Federal, a Comissão de Assuntos Sociais do Senado e a Associação dos M embros dos Tribunais de Contas (Atricon).

Essa articulação, que existia em maior ou menor grau, durante as negociações para a aprovação da emenda, foi reforçada logo após sua publicação devido à necessidade do estabelecimento dos recursos do M inistério da Saúde para o ano seguinte, ou seja, 2001.

0 texto constitucional não deixava dúvidas em relação ao montante a ser destinado à saúde no ano 2000. Segundo 0 art. 70, inciso I, letra "a", esse valor seria o equivalente ao montante empenhado em ações e serviços públicos de saúde acrescido de, no mínimo, cinco por cento. U ma vez que a emenda só foi publicada ao fim do ano de2000, este não era um problema quefoi, de fato, gerado, porque a destinação havia sido maior do que o percentual de acréscimo estabelecido. Cabe explicar: a letra "b" do artigo einciso mencionados estabelece que serão destinados recursos mínimos para a saúde equivalentes a, "do ano 2001 ao ano 2004, o valor apurado no ano anterior, corrigido pela variação nominal do PIB".

Ora, no momento de decidir o orçamento da saúde para o ano de 2001, o M inistério da Fazenda, através de sua Procuradoria Jurídica, emitiu o parecer PGFN/CAF n. 2.561/2000, de 7 de dezembro de 2000, que continha 0 entendimento de que a referência para 0 "ano anterior" é, de fato, para 2001, "o valor calculado na forma do art. 7ọ, I, A, do Ato das Disposições Constitucionais Transitórias (ADCT)", ou seja, 0 ano de 1999 acrescido de 5\%, aplicando-se, daí por diante, a variação do PIB. Desse modo, o parecer "congelou" o orçamento do Ministé rio da Saúde entendendo que, ainda mesmo em 2004, o "ano anterior" é 1999 (acrescido de 5\%).

À época, cál culos da Secretaria Executiva do M inistério da Saúde indicaram que as perdas de recursos passíveis de serem acumuladas no período entre 2001 e 2002, caso fosse considerado 0 entendimento da Fazenda, seria de até $R \$ 4,2$ bilhões de reais (Abrasco, 2001).

Esse foi o estopim para a rearticulação dos atores mencionados anteriormente, cujo resultado foi não apenas um embate jurídico com o Ministério da Fazenda, mas também a produção do primeiro documento sobre a regulamentação da emenda, intitulado "Parâmetros consensuais sobre a implementação eregulamentação da EC 29" (2001). Além da questão do "ano anterior", o documento contemplou outros aspectos polêmicos ou pouco esclarecidos da emenda.

Entre os aspectos de maior consenso estavam os seguintes:

- a definição de quais receitas de estados emunicípios devem ser vinculadas às ações e serviços de saúde, uma vez que estão bem especificadas, quais sejam, os impostos diretamente arrecadados, acrescidas e reduzidas as transferências legais e constitucionais recebidas e pagas, respectivamente;

- o período de vigência da emenda, que por ser auto-aplicável, já deveria viger em 2000, mas não havia tempo para suplementações substanciais nos orçamentos e, portanto, acordou-se sua vigência a partir do ano de 2001;

- os percentuais mínimos de vinculação de receitas por estados e municípios e sua evolução até 2004, partindo-se do patamar de 7\% para ambos e chegando à diferença mínima anual de $1 / 5$, até $12 \%$ e $15 \%$, respectivamente;

- a variação do PIB a ser utilizada no cálculo da evolução da União, uma vez que os dados são divulgados pelo IBGE com defasagem em relação às decisões sobre orçamentos, tendo-se optado pela utilização do PIB disponível quando da votação da Lei Orçamentária;

- o acompanhamento, avaliação e controle da emenda, cujo instrumento principal foi definido como sendo o Sistema de Informações sobre Orçamentos Públicos de Saúde (Siops), abrangendo também os próprios Planos de Saúde e os Relatórios de Gestão da Saúde e Fiscais (previstos, os últimos, na Lei de Responsabilidade Fiscal).

Por outro lado, alguns aspectos continuaram nebulosos e demandaram, ao longo do ano de 2001 e em 2002, a realização de novos encontros do grupo, dessa vez expandidos pela presença de membros dos Tribunais de Contas. Foram realizados três seminários sobre a O peracionalização da Emenda Constitucional n. 29/ 00, não apenas na busca de esclarecimentos, mas 
também para a troca de informações e divulgação dos consensos até então al cançados.

U $m$ dos principais entraves à implementação do texto constitucional e, conseqüentemente, do acompanhamento de seu cumprimento é a definição do que são "ações e serviços públicos de saúde". Conceito aparentemente conhecido de todos nos debates, ficam evidentes as distintas compreensões do escopo do termo - ele inclui ou não ações de saneamento, inclui ou não o pagamento de dívidas contraídas para financiamento de ações de saúde, inclui ou não o pagamento de pessoal aposentado e de pensionistas da saúde?

Se tais definições não estiverem regulamentadas, a aplicação de recursos adicionais decorrente da implementação do texto da Carta M agna poderá ser comprometida. Até o momento, como resultado das discussões supramencionadas, foi aprovada, pelo Conselho $\mathrm{N}$ acional de Saúde, a resolução n. 316, de 4 de abril de 2002, que dispõe sobre dez diretrizes acerca da aplicação da emenda.

A 5 a diretriz define três critérios para o que deve ser considerado como despesa com ações e serviços públicos de saúde:

- sejam destinadas às ações e serviços de acesso universal, igualitário e gratuito;

- estejam em conformidade com objetivos e metas explicitados nos Planos de Saúde de cada ente federativo;

- sejam de responsabilidade específica do setor de saúde, não se confundindo com despesas relacionadas a outras políticas públicas que atuam sobre determinantes sociais e econômicos, ainda que com reflexos sobre as condições de saúde.

$\mathrm{Na}$ 6a diretriz tais despesas são detalhadas por tipo de ação, incluindo aquelas tradicionalmente desenvolvidas no setor, relativas à promoção, proteção, recuperação e reabilitação da saúde, conforme disposto na Lei Orgânica da Saúde, com destaque para dois itens:

- inciso XII: saneamento básico e do meio ambiente, desde que associado ao controle de vetores, a ações próprias de pequenas comunidades ou em nível domiciliar, ou aos Distritos Sanitários Especiais Indígenas (DSEI), e outras ações de saneamento a critério do Conselho $\mathrm{Nacional}$ de Saúde, e

- inciso XII: serviços de saúde penitenciários, desde que firmado Termo de Cooperação específico entre os órgãos de saúde e os órgãos responsáveis pela prestação dos referidos serviços.

Ações e serviços de saneamento e os voltados para clientelas delimitadas estão no rol de des- pesas que, se não estiverem muito bem delimitadas, podem acarretar impactos negativos sobre o dispositivo constitucional em termos de aporte de recursos.

Durante as discussões com os Tribunais de Contas, ficou claro que os gastos referentes a pagamento de amortização e encargos de dívidas contraídas para o financiamento setorial devem necessariamente compor os gastos com ações e serviços públicos de saúde, inclusive para efeitos da Lei de Responsabilidade Fiscal. Contudo, isso foi previsto apenas como uma excepcionalidade nos parágrafos 10 e 20 da $6 a$ diretriz.

Finalmente, a 7a diretriz dispõe sobre o que não é considerado ações e serviços públicos de saúde, nela estando incluídos o pagamento de aposentadorias e pensões, a assi stência à saúde para clientel as fechadas, o saneamento básico financiado por tarifas ou taxas, a limpeza urbana e outras.

0 processo de regulamentação do texto constitucional alterado pela EC 29/00 está apenas no seu início mas, em que pesem as dificuldades e controvérsias que já existem e virão ainda a existir, acredita-se que nesse processo estados e municípios poderão vir a ter ganhos importantes em termos de autonomia financeira no campo da saúde, ainda que com a coordenação fundamental da U nião e, se e quando possível, dos estados.

\section{0 gasto público com saúde em 2000 e perspectivas}

Pesquisa realizada a partir de dados do Sistema de Informações sobre Orçamentos Públicos em Saúde (Siops) e da Secretaria Executiva, ambos do M inistério da Saúde (Faveret, 2002) apontam que os recursos destinados pelos três níveis de governo, com suas receitas próprias, às ações e aos serviços públicos de saúde, conforme os consensos mencionados na seção anterior, somaram em 2000 cerca de 37 bilhões de reais, a valores de 2001, para os quais a União contribuiu com $59 \%$, e os estados e municípios com, respectivamente, $18,2 \%$ e $22,7 \%$.

A tabela 1 apresenta esses dados em valores por habitante e com o percentual do PIB. Além disso, indica os percentuais de cumprimento do dispositivo constitucional de vinculação de receitas a gastos em saúde de estados emunicípios.

O gasto público com saúde representou, portanto, em 2000, 3,17\% do PIB brasileiro, equivalendo a $\mathrm{R} \$ 216,99$ por habitante no ano. 
Tabela 1

Gasto público com ações e serviços de saúde empenhado pelas três esferas de governo - total, per capita, participação no PIB, distribuição entre esferas e cumprimento EC 29/00 - 2000. Em R \$ de 2001 e percentual

\begin{tabular}{lccccc}
\hline Esfera de governo & Total (R\$) & Per capita (R\$) & \% PIB & \% Esferas & \% EC 29 \\
\hline União & $21.743 .629 .992,03$ & 128,05 & 1,87 & 59,02 & N.A. \\
Estados & $6.717 .934 .391,00$ & 39,56 & 0,58 & 18,23 & 7,1 \\
M unicípios & $8.382 .650 .908,49$ & 49,37 & 0,72 & 22,75 & 13,2 \\
Brasil & $36.844 .215 .291,52$ & 216,99 & 3,17 & 100,00 & N.A. \\
\hline
\end{tabular}

Fonte: M inistério da Saúde.

N otas: (1) Valores em reais de 2001 atualizados pelo IPCA. (2) Os valores da U nião excluem os gastos com dívidas, inativos, pensionistas e ações de saneamento do Projeto Alvorada. Elaboração própria.

Segundo dados do Banco Federativo (BNDES, 2002), a distribuição das receitas disponíveis totais em 2000 por parte dos entes federados era de $62,71 \%$ para a União, $24,56 \%$ para os estados e $12,73 \%$ para os municípios, o que comprova que foram os últimos os que, proporcionalmente, mais investiram em saúde naquele ano.

De fato, o processo de descentralização das receitas, implementado a partir da Constituição Federal de 1988, foi acompanhado, no campo da saúde, da descentralização de encargos que avançou especialmente no âmbito municipal, comprovado pelo aumento do aporte de recursos dos municípios ao setor.

A figura 1 compara os dados de $2000 \mathrm{com}$ os apurados por M édici (1994) e por Biasoto \& Piola (2001), e demonstra a evolução da partici pação das três esferas de governo no financiamento público da saúde.

Não obstante todas as dificuldades metodológicas encontradas na comparação de séries de dados financeiros, pode-se verificar as tendências, ao longo dos anos 90, de redução acentuada da participação da U nião no financiamento público da saúde, de aumento pouco expressivo da participação dos estados, e de grande aumento da participação municipal, que praticamente dobrou entre 1992 e 2000.

A Emenda Constitucional n. 29/00 aporta um novo componente para o financiamento do sistema de saúde que parece indicar, em princípio, ganhos em termos de volume e estabilidade dos recursos destinados pelo setor, através da consolidação do mecanismo de co-financiamento.

M ediante a utilização de metodologia de estimativa do impacto da implementação do dispositivo constitucional acerca da vinculação de recursos para a saúde (Faveret et al., 2001), prevê-se até 2004, considerando-se os valores aci- ma determinados para 0 ano de 2000, um aporte adicional de recursos da ordem de $R \$ 11,4$ biIhões, a valores de 2001, conforme a tabela 2.

De modo resumido a metodologia de estimativa consiste em:

- Para a União: no ano de 2000, o montante mínimo aplicado em ações e serviços públicos de saúde deveria ser acrescido de $5 \%$ em relação a 1999 (o que aconteceu). Nos anos seguintes, entre2001 e 2004, 0 aumento das despesas está vinculado à variação nominal do PIB; estimado para o período como de $4 \%$ ao ano a partir de 2002. - Para os estados e municípios: os percentuais mínimos de vinculação de sua receita de impostos deverão chegar a $12 \%$ e $15 \%$ em 2004, respectivamente. Para o ano 2000, estipulou-se o valor mínimo de aplicação em 7\%. Dessa forma, buscou-se um aumento gradual para os gastos em saúde dos entes federados, visando minimizar as disparidades em relação aos valores despendidos em ações e serviços públicos de saúde pelas esferas subnacionais.

- Os dados estaduais foram extraídos de seus balanços e os munici pais foram calculados a partir de um painel contendo dados de 2.550 dos 3.252 municípios que informaram o Siops (ano-base 2000 ), que abrange $46,3 \%$ do número de municípios brasileiros e $64,5 \%$ da população brasileira em 2000.

Está claro que o maior impacto da vinculação constitucional será sobre as contas estaduais, cujos gastos com saúde deverão crescer $71 \%$ até2004. Paraa União e os municípios, 0 aumento de recursos até 2004 será da ordem de $17 \%$ e $37 \%$, respectivamente, resultando aumento total de $31 \%$ para as três esferas de governo.

0 acentuado impacto sobre os estados e 0 menor impacto sobre os municípios decorre da evolução do formato federativo do sistema de saúde brasileiro vis-à-vis o formato das relações 
Figura 1

Evolução da participação das três esferas de governo no gasto público com saúde - 1992, 1996 e 2000

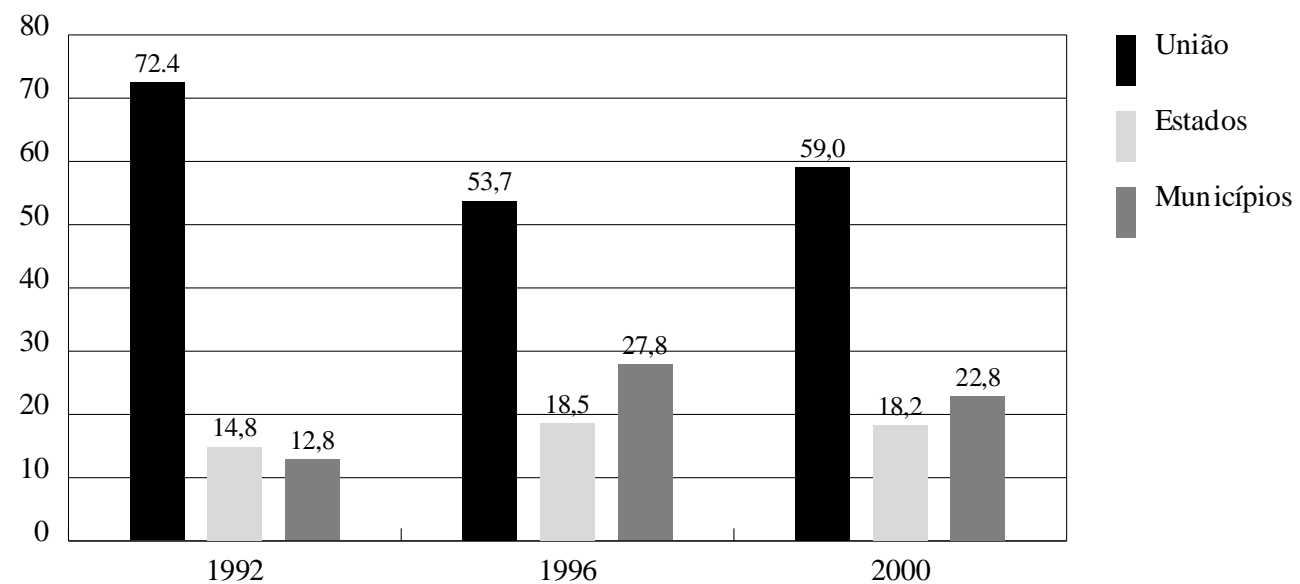

Fonte: M inistério da Saúde, Biasoto \& Piola, 2001 e M édici, 1994. Elaboração própria.

Tabela 2

Impacto da Emenda Constitucional n. 29/2000, por esfera de governo.

Em R\$ milhões de 2001 e percentual

\begin{tabular}{lcccc}
\hline Esfera de governo & $\begin{array}{c}\text { Empenhado } \\
\mathbf{2 0 0 0}(\mathbf{R} \mathbf{\$})\end{array}$ & $\begin{array}{c}\text { Estimativa } \\
\mathbf{2 0 0 4}(\mathbf{R} \mathbf{)}\end{array}$ & $\begin{array}{c}\text { Adicional EC } \\
\mathbf{2 9} \mathbf{0 0 / 0 4}(\mathbf{R} \mathbf{\text { ) }}\end{array}$ & $\begin{array}{c}\text { Adicional EC } \\
\mathbf{2 9} \mathbf{0 0 / 0 4}(\mathbf{\%})\end{array}$ \\
\hline União & 21.744 & 25.338 & 3.594 & 17 \\
Estados & 6.718 & 11.482 & 4.764 & 71 \\
M unicípios & 8.383 & 11.474 & 3.091 & 37 \\
Brasil & 36.844 & 48.294 & 11.450 & 31 \\
\hline
\end{tabular}

Fonte: M inistério da Saúde - SIS/CGOP-SIOPS.

Notas: (1) Valores atualizados pelo IPCA. (2) Os valores da U nião excluem os gastos com dívidas, inativos, pensionistas e ações de saneamento do Projeto. Elaboração própria.

federativas de caráter fiscal estabelecidas ao longo da década de 1990, que fortaleceram as finanças municipais em detrimento das estaduais.

Assim, entende-se que, por um lado, a intensificação do processo de municipalização da saúde, principalmente a partir da Norma Operacional Básica de 1993, aliada à reforma fiscal implementada na própria Constituição Federal, teve como conseqüência natural a elevação dos gastos dos municípios na área da saúde ao Iongo dos anos 90 .

Por outro lado, o oposto ocorreu com os estados durante a década passada, já que não tiveram seu papel claramente definido na legislação infraconstitucional do SUS, em particular nas suas $\mathrm{N}$ ormas $\mathrm{O}$ peracionais Básicas. $\mathrm{N}$ ão bastasse isso, passaram por um intenso processo de reestruturação financeira, com maior comprometimento de suas receitas com o pagamento de suas dívidas internas. Esses dois fatores contribuíram sobremaneira para a reduzida participação dos estados no total de gastos públicos com saúde no período.

Registre-se que a Emenda Constitucional $n$. 29/00, além de garantir recursos adicionais para a saúde, teve como importante avanço a responsabilização de todos os entes federados com o financiamento do SUS, ilustrada na figura 2. 
Figura 2

Participação percentual das três efferas de governo na despesa com saúde - 2000 e estimativas para 2004

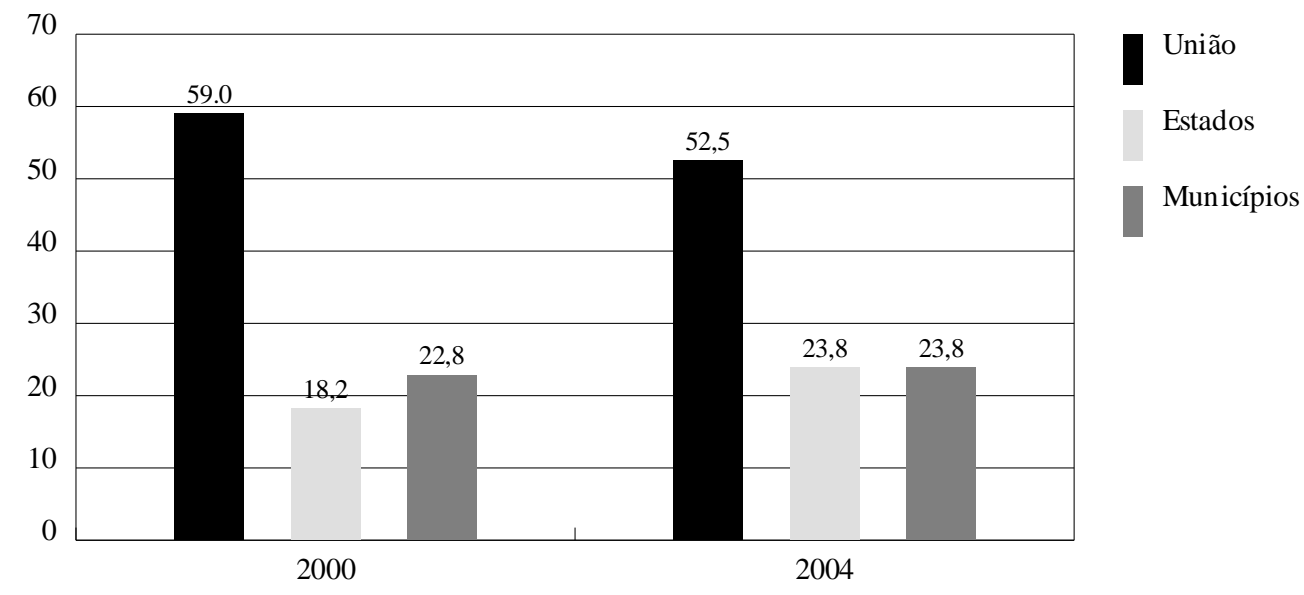

Fonte: M inistério da Saúde - SIS/CGOP-SIOPS. Elaboração própria.

Ademais, cabe lembrar que a simples vinculação não significa, por si só, a redução de desigualdades e tampouco a solução para problemas relacionados à equidade, em especial na saúde, que depende de uma complexa organização da rede e, também, de uma rede de complexas organizações, que envolve múltiplos atores e diferentes interesses. A vinculação, de fato, apenas garante que os estados e os municípios venham a se colocar em um mesmo ponto de partida no que tange ao gasto com saúde e, com isso, tenham a possibilidade de ter maior autonomia na forma de executar o gasto, definindo seus modelos assistenciais próprios.

Por outro lado, é importante ressal tar que a intensa e extensa normatização levada a cabo pelo M inistério da Saúde, ao mesmo tempo em que engessa a atuação de estados e municípios, permite em boa parte a superação de uma série de dificuldades organizativas enfrentadas pelos gestores subnacionais.
Note-se que a estratégia de relacionamento direto da União com os municípios pode ser também um tanto atribuída aos próprios governos estaduais, pela ausência, inclusive, no que tange ao financiamento. Essa situação poderá ser parcialmente revertida a partir da aplicação dos novos dispositivos constitucionais.

Por fim, na perspectiva da U nião, a Emenda Constitucional n. 29/00 torna irrelevante, a partir da indexação ao crescimento do PIB, a forma de financiar a receita federal destinada à saúde. Em outras palavras, isso poderá implicar o esvaziamento definitivo do Orçamento da Seguridade Social cuja base, formada pelas contribuições sociais, dissociou o acesso às políticas sociais das contribuições individuais, e concretizou, na Constituição Federal de 1988, do ponto de vista do financiamento, a universalização deste conjunto de direitos. 


\section{Referências bibliográficas}

Abrasco 2001. A Emenda pior que o soneto? Rio de Janeiro, Boletim Abrasco 83, ano XVIII:2-4.

Biasoto G \& Piola S 2001. Finanças e dispêndios: financiamento do SUS, gasto público e base tributária, pp. 219-232. In B N egri \& G Giovanni. Brasil: radiografia da saúde. Unicamp, Campinas.

BNDES 2002. Banco Federativo. <http://www.bndes bancofederativo>. Acesso em 15 de maio de 2002 (Termômetro da descentralização).

Brasil 1988. Constituição da República Federativa do Brasil. Senado, Brasília.

Conselho Nacional deSaúde. Resolução n. 316, de 4 de abril de 2002. Aprova diretrizes acerca da aplicação da Emenda Constitucional n. 29/00.

Dain S et al. 2001. Avaliação dos impactos de reforma tributária sobre o financiamento da saúde, pp. 233-290. In B N egri \& G Giovanni. Brasil: radiografia da saúde. Unicamp, Campinas.

Emenda Constitucional n. 29, de 13 de outubro de 2000. Altera a Constituição Federal para assegurar os recur- sos mínimos para o financiamento das ações e serviços públicos de saúde.

Faveret AC et al. 2001. Estimativas de impacto da vinculação constitucional de recursos para a saúde. Cadernos de Economia da Saúde série J, n. 4.

Faveret AC 2002. Federalismo fiscal e descentralização no Brasil: o financiamento da política de saúde na década de 90 e início dos anos 2000. Tese de doutorado em saúde coletiva. Programa de Pós-Graduação em Saúde Coletiva, Instituto de M edicina Social, Universidade do Estado do Rio de Janeiro, Rio de Janeiro.

M édici AC 1994. Economia e financiamento do setor saúde no Brasil: balanços e perspectivas do processo de descentralização. Faculdade de Saúde Pública, São Paulo.

M inistério da Saúde et al. 2001. Parâmetros consensuais sobre a implementação e regulamentação da EC 29. Brasília (M imeo).

Artigo apresentado em 10/10/2002

Aprovado em 10/2/2003

Versão final apresentada em 6/4/2003 